\title{
Reproduction in Dairy Cows Following Progesterone Insert Presynchronization and Resynchronization Protocols
}

\author{
R. C. Chebel, J. E. P. Santos, ${ }^{1}$ R. L. A. Cerri, H. M. Rutigliano, and R. G. S. Bruno \\ Veterinary Medicine Teaching and Research Center, University of California-Davis, Tulare 93274
}

\section{ABSTRACT}

The objectives of this study were to evaluate the effects of an intravaginal insert containing progesterone (CIDR, controlled internal drug releasing) administered in presynchronization and resynchronization protocols on cyclicity, detection of estrus, pregnancy rate, and pregnancy loss to first AI; reinsemination patterns; and pregnancy rates to second postpartum AI before and after the time of first-service pregnancy diagnosis in dairy cows. Holstein cows $(\mathrm{n}=1,052)$ were blocked by parity and BCS at $3 \pm 3 \mathrm{~d}$ in milk (study d $0=$ day of calving) and assigned randomly to 1 of 3 presynchronization treatments. During the presynchronization programs, all cows received 2 injections of $\mathrm{PGF}_{2 \alpha}$, on study d 35 and 49 . Cows enrolled in the control presynchronization treatment received AI after detected estrus from study d 49 to 62 . Cows enrolled in the CIDR estrus-detection (CED) presynchronization treatment received a CIDR insert from study d 42 to 49 and AI on detection of estrus from d 49 to 62 . Cows enrolled in the CIDR timed AI (CTAI) presynchronization treatment received the same treatment as CED, but were subjected to timed AI on study d 72 after the Ovsynch (GnRH, $7 \mathrm{~d} \mathrm{PGF}_{2 \alpha}, 2 \mathrm{~d}$ GnRH, $24 \mathrm{~h}$ timed AI) protocol. The control and CED cows not inseminated by study d 62 were enrolled in the Ovsynch protocol on the same day and received timed AI on study d 72. After first AI, cows were assigned to no resynchronization (RCON) or resynchronization with a CIDR insert (RCIDR) between 14 and $21 \mathrm{~d}$ after AI. Blood samples collected on study d 35, 49, and 62 were analyzed for concentrations of progesterone and cows were classified as anestrous when progesterone was $<1.0 \mathrm{ng} / \mathrm{mL}$ in the first $2 \mathrm{sam}$ ples. On study d 62 , anestrous cows with progesterone $\geq 1.0 \mathrm{ng} / \mathrm{mL}$ were classified as having resumed cyclicity. Pregnancy was diagnosed at 31 and $60 \mathrm{~d}$ after first AI and at $42 \mathrm{~d}$ after second AI. A greater proportion of anestrous cows in CED and CTAI became cyclic by $d$ 62 postpartum than control cows. Resynchronization

Received March 17, 2006.

Accepted June 12, 2006.

${ }^{1}$ Corresponding author: Jsantos@vmtrc.ucdavis.edu with the CIDR insert increased the pregnancy rate at $31 \mathrm{~d}$ after first AI in CED and CTAI, and at $60 \mathrm{~d}$ after $\mathrm{AI}$ in all cows because of reduced pregnancy loss. These results indicate that presynchronization with the CIDR insert increased induction of cyclicity in anestrous cows and that resynchronization with the CIDR insert did not affect the reinsemination rate but did reduce pregnancy loss and increased the pregnancy rate at $60 \mathrm{~d}$ after first AI.

Key words: dairy cow, progesterone, presynchronization, resynchronization

\section{INTRODUCTION}

Adoption of systematic breeding programs by dairy herds allows for greater control of AI of cows that reach the end of the voluntary waiting period. Use of ovulation synchronization programs for timed AI (TAI) has resulted in acceptable conception rates with maximal submission to AI after the end of the voluntary waiting period (Pursley et al., 1997; Moreira et al., 2001; Cerri et al., 2004). A presynchronization protocol with 2 injections of $\mathrm{PGF}_{2 \alpha}$ administered $14 \mathrm{~d}$ apart with initiation of the TAI protocol $12 \mathrm{~d}$ (Moreira et al., 2001) or 14 d later (Navanukraw et al., 2004) was developed to optimize the response to TAI protocols.

The presynchronization protocol based on $\mathrm{PGF}_{2 \alpha}$ developed by Moreira et al. (2001) has limited efficacy in anestrous cows, because response to injections of $\mathrm{PGF}_{2 \alpha}$ depends on the presence of a responsive corpus luteum (CL). The prevalence of anestrous cows at approximately 50 to 60 DIM in US dairy herds varies from $20 \%$ to more than 40\% (Moreira et al., 2001; Cerri et al., 2004; El-Zarkouny et al., 2004), which can compromise the response to presynchronization programs based solely on $\mathrm{PGF}_{2 \alpha}$ (Moreira et al., 2001). Cows classified as anestrous immediately before enrollment in an AI program have decreased reproductive performance because of decreased expression of estrus and conception rate (Rhodes et al., 2003; Cerri et al., 2004; Galvão et al., 2004) and increased embryonic and fetal losses (Santos et al., 2004b). Therefore, failure to resume normal estrous cycles by 50 to $60 \mathrm{~d}$ postpartum limits the efficacy of synchronization programs and reduces the reproductive efficiency of lactating dairy cows. 
Intravaginal progesterone inserts can be used to induce cyclicity in anestrous cows and heifers (Rhodes et al., 2003), and to synchronize return to estrus in nonpregnant cows (Chenault et al., 2003). However, induction of cyclicity with intravaginal progesterone inserts has not been evaluated in high-producing lactating dairy cows. Furthermore, the use of these inserts during presynchronization programs to influence detection of estrus and pregnancy has not been evaluated.

Cows enrolled in the Ovsynch protocol (Pursley et al., 1997) after presynchronization with $\mathrm{PGF}_{2 \alpha}$ (Moreira et al., 2001) for first AI are, in some cases, inseminated on detection of estrus following the presynchronization program (Stevenson and Phatak, 2005). It is not clear whether AI on detection of estrus after the presynchronization with $\mathrm{PGF}_{2 \alpha}$ poses advantages compared with submitting all cows to TAI, because the former allows some cows to be inseminated 2 to 3 wk earlier. In addition, combining programs for first AI with early resynchronization of nonpregnant cows might improve reproductive performance of lactating cows (Chenault et al., 2003; El-Zarkouny and Stevenson, 2004).

The hypotheses of the present study were that use of an intravaginal progesterone insert during a presynchronization protocol with $\mathrm{PGF}_{2 \alpha}$ would result in an increased proportion of anestrous cows initiating cyclicity, which was expected to improve pregnancy rates in lactating cows. In addition, avoiding AI during the presynchronization period might result in increased conception rates. Finally, incorporating the intravaginal progesterone insert from 14 to $21 \mathrm{~d}$ after first AI to synchronize the return to estrus might increase the reinsemination rate of nonpregnant cows before pregnancy diagnosis at $31 \mathrm{~d}$ post AI.

Therefore, our objectives were 1) to determine the effects of inclusion of an intravaginal progesterone insert during the presynchronization protocol on initiation of cyclicity and reproductive responses; 2 ) to evaluate the effect on conception rate and pregnancy losses of subjecting all cows to TAI; and 3) to evaluate the efficacy of an intravaginal progesterone insert to synchronize returns to estrus and reinsemination of nonpregnant lactating dairy cows before pregnancy diagnosis.

\section{MATERIALS AND METHODS}

\section{Cows, Housing, and Diets}

The University of California-Davis Institutional Animal Care and Use Committee approved all procedures involving cows. Lactating Holstein cows $(\mathrm{n}=1,052)$ from a commercial dairy farm with 3,200 lactating dairy cows and a rolling herd milk production average of $12,035 \mathrm{~kg}$ of $3.5 \%$ FCM located in the San Joaquin
Valley of California were used in this study. Cows were housed in free-stall barns and individual pens were virtually identical in design, size, and number of cows housed. Of the 1,052 lactating dairy cows initially enrolled in the study, 75 were removed because of poor udder conformation $(\mathrm{n}=17)$, uterine and ovarian adhesions $(n=9)$, and death $(n=36)$ or were sold $(n=13)$ before the end of the voluntary waiting period on study $\mathrm{d} 49$. Therefore, a total of 977 cows were used for statistical analyses.

Cows were fed 2 different diets as TMR according to the stage of lactation, with an immediate postpartum diet fed between 1 and 21 DIM, and a lactating diet for the remainder of lactation. Cows were fed twice daily and diets were based on corn silage, alfalfa hay, soybean meal, steam-rolled corn, whole cottonseed, calcium salts of palm oil, and a mineral, vitamin, and protein supplement. The 2 diets were designed to meet or exceed NRC (2001) requirements for lactating Holstein cows weighing $650 \mathrm{~kg}$ and producing $45 \mathrm{~kg}$ of milk/d, containing $3.5 \%$ fat.

Weekly, approximately $0.5 \mathrm{~kg}$ of TMR was sampled and dried at $55^{\circ} \mathrm{C}$ for $48 \mathrm{~h}$ in an air-circulating oven. Dried samples were then ground in a Wiley mill (Arthur H. Thomas Co., Philadelphia, PA) to pass a $2-\mathrm{mm}$ screen, and then in a cyclone mill (Udy Co., Fort Collins, $\mathrm{CO})$ to pass a 1-mm screen. Samples were then composited for 2-mo periods and analyzed for contents of DM at $105^{\circ} \mathrm{C}, \mathrm{OM}, \mathrm{ADF}, \mathrm{NDF}$, and minerals. The $\mathrm{N}$ content of samples was analyzed using an N analyzer (FP-528 Nitrogen Determinator; LECO Corporation, St. Joseph, $\mathrm{MI}$ ), and $\mathrm{CP}$ was calculated by multiplying the $\mathrm{N}$ content by 6.25. Mineral content was analyzed at the Dairyland Laboratory (Arcadia, WI) using an Applied Research Laboratories inductively coupled plasma mass spectrometer (Thermo Jarrell Ash, Franklin, MA). During the first 21 DIM, the TMR contained (DM basis) $91.5 \%$ OM, $18.3 \%$ CP, $5.4 \%$ ether extract, $33.0 \%$ NDF, $37.7 \%$ nonfibrous carbohydrates, $1.16 \% \mathrm{Ca}$, $0.46 \% \mathrm{P}, 0.35 \% \mathrm{Mg}, 1.60 \% \mathrm{~K}, 0.25 \% \mathrm{~S}, 0.50 \% \mathrm{Na}$, and $0.56 \% \mathrm{Cl}$. For the remainder of the lactation, the TMR contained $92.5 \% \mathrm{OM}, 17.0 \% \mathrm{CP}, 5.3 \%$ ether extract, $32.8 \% \mathrm{NDF}, 40.0 \%$ nonfibrous carbohydrates, $0.84 \%$ $\mathrm{Ca}, 0.44 \% \mathrm{P}, 0.33 \% \mathrm{Mg}, 1.49 \% \mathrm{~K}, 0.23 \% \mathrm{~S}, 0.47 \% \mathrm{Na}$, and $0.47 \% \mathrm{Cl}$.

\section{Presynchronization Treatments}

Weekly, cows were blocked by parity, BCS at $3 \pm$ 3 DIM (study d 3), and previous lactation milk yield (multiparous), and within each block were randomly assigned to 1 of 3 presynchronization treatments (Figure 1). All cows received one injection of $25 \mathrm{mg}$ of $\mathrm{PGF}_{2 \alpha}$ (dinoprost tromethamine; $5 \mathrm{~mL}$ of Lutalyse Sterile So- 


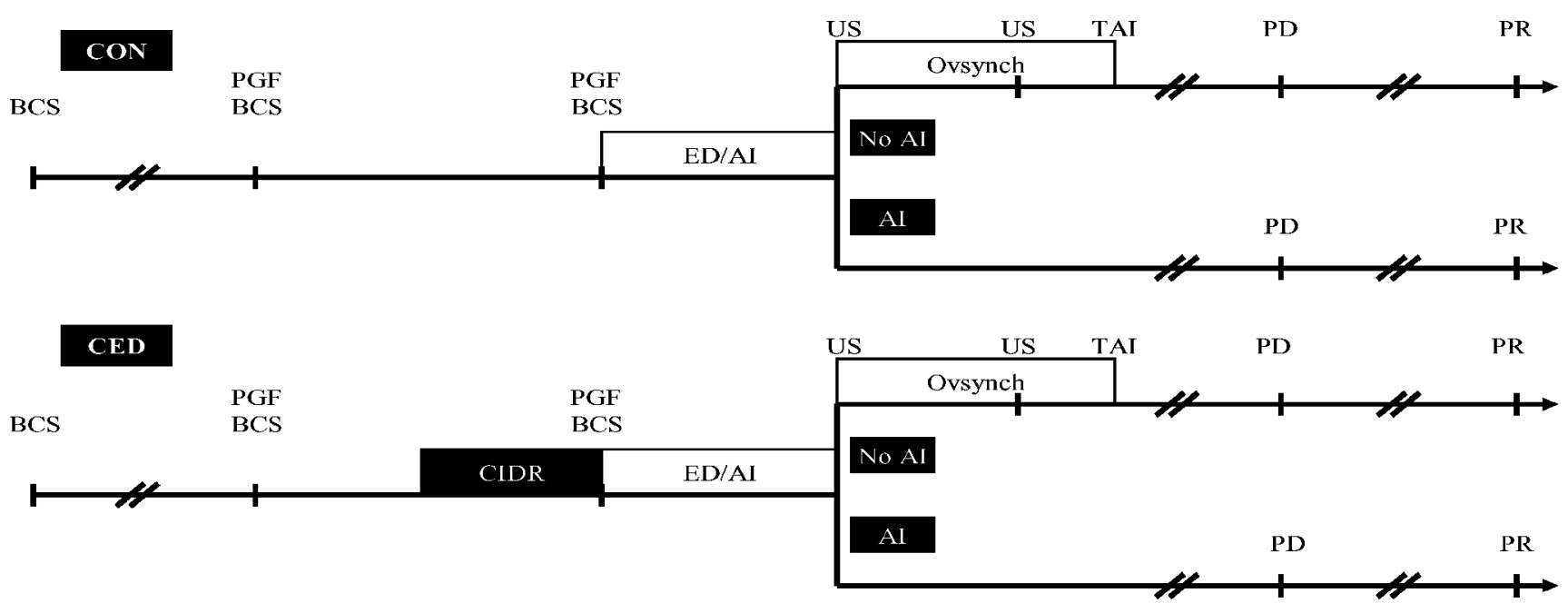

\section{CTAI}

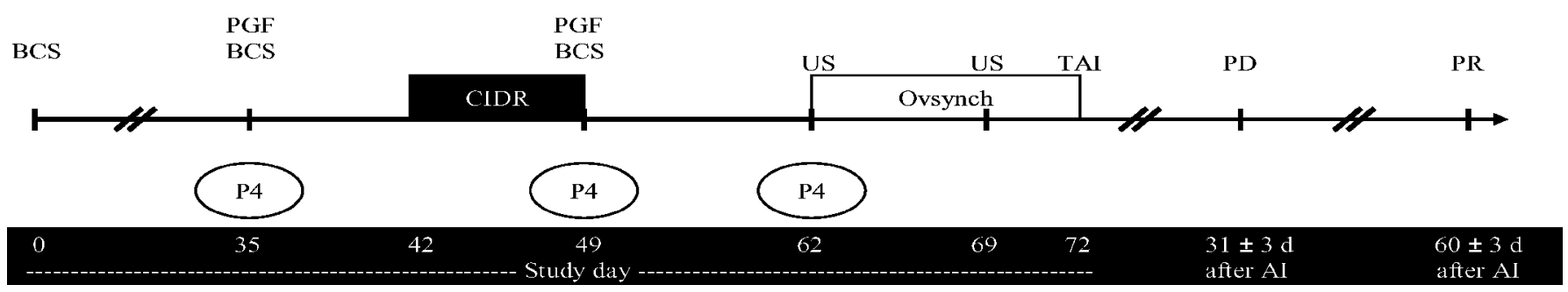

Figure 1. Diagram of activities at first AI. All cows received 2 injections of $\mathrm{PGF}_{2 \alpha}$ on study d 35 and 49 , and study d 49 was set as the end of the voluntary waiting period for all treatments. CON = AI on detection of estrus from study d 49 to 62 ; CED = controlled internal drug releasing (CIDR) insert from study d 42 to 49 and AI on detection of estrus from study d 49 to 62 ; CTAI = same as CED, but all cows received timed AI (TAI) on study d 72 after completion of the Ovsynch protocol. CIDR = intravaginal progesterone insert containing 1.38 $\mathrm{g}$ of progesterone; $\mathrm{ED}=$ detection of estrus; Ovsynch = injection of $100 \mu \mathrm{g}$ of $\mathrm{GnRH}$, followed $7 \mathrm{~d}$ later by an injection of $25 \mathrm{mg}$ of PGF ${ }_{2 \alpha}$, and a second injection of $100 \mu \mathrm{g}$ of $\mathrm{GnRH} 48 \mathrm{~h}$ later; $\mathrm{PGF}=25 \mathrm{mg}$ of $\mathrm{PGF}_{2 \alpha}$; P4 = blood sample collected for analysis of progesterone concentration; $\mathrm{PD}=$ pregnancy diagnosis; $\mathrm{PR}=$ pregnancy reconfirmation; TAI = timed $\mathrm{AI}(24 \mathrm{~h}$ after the second GnRH injection of the Ovsynch protocol); US = ultrasound examination of the ovaries.

lution; Pfizer Animal Health, New York, NY), on study d 35 and 49. Study d 49 was designated as the end of the voluntary waiting period for all cows. Cows enrolled in the control (CON) presynchronization treatment received no further treatment and were inseminated on detection of estrus from study d 49 to $62(\mathrm{n}=353)$; cows enrolled in the CIDR (controlled internal drug releasing) estrus-detection (CED) presynchronization treatment received an intravaginal insert (Eazi-Breed CIDR Cattle Insert; Pfizer Animal Health) containing $1.38 \mathrm{~g}$ of progesterone from study d 42 to 49 and were inseminated on detection of estrus from study d 49 to $62(\mathrm{n}=350)$; and cows enrolled in the CIDR TAI (CTAI) presynchronization treatment received the same treatment as CED, but cows were not inseminated following removal of the CIDR insert $(\mathrm{n}=349)$. On study $\mathrm{d} 62$ all cows from the CTAI treatment and cows from the CON and CED treatments not yet observed in estrus were enrolled in the Ovsynch protocol (Pursley et al.,
1997) with a slight modification. They received an injection of $100 \mu \mathrm{g}$ of $\mathrm{GnRH}$ (gonadorelin diacetate tetrahydrate, Cystorelin; Merial, Ltd., Iselin, NJ) on study d 62 , followed $7 \mathrm{~d}$ later by an injection of $25 \mathrm{mg}$ of $\mathrm{PGF}_{2 \alpha}$, and a second injection of $100 \mu \mathrm{g}$ of $\mathrm{GnRH} 48 \mathrm{~h}$ later (study d 71), and then TAI $24 \mathrm{~h}$ after the final injection of GnRH (study d 72).

\section{Resynchronization Treatments}

Once weekly, on Thursdays, cows between 13 and $15 \mathrm{~d}$ after first AI were blocked by presynchronization treatment, and within each block, were randomly assigned to receive no resynchronization treatment (RCON) or to receive a CIDR insert for $7 \mathrm{~d}$ (RCIDR) starting at $14 \pm 1 \mathrm{~d}$ after AI (Chenault et al., 2003). Based on initial presynchronization treatments, the majority of cows were expected to be inseminated on Wednesday through Friday, because the $\mathrm{PGF}_{2 \alpha}$ injec- 
tions and CIDR insert removal during presynchronization occurred on Tuesdays, and because TAI was performed once a week on Thursdays. Therefore, $84.7 \%$ $(\mathrm{n}=828)$ of the cows enrolled in the study received their first AI on Wednesday through Friday. Because of that, 149 cows inseminated on Saturday through Tuesday were evaluated to determine whether their data could be included in the analysis for the RCON resynchronization treatment. There was no effect $(P$ $>0.70$ ) of day of the week when first AI occurred or interaction $(P>0.15)$ between day of the week and presynchronization protocol on the pregnancy rate to first $\mathrm{AI}$ or on pregnancy loss between 31 and $60 \mathrm{~d}$ after AI for cows enrolled in the CON or CED presynchronization treatments. Furthermore, day of the week had no effect $(P>0.15)$ on second AI conception rate for $\mathrm{CON}$ and CED cows. Therefore, cows from the CON and CED treatments inseminated between Saturday and Tuesday were allocated into the RCON resynchronization treatment, which resulted in 603 cows assigned to the RCON and 374 to the RCIDR resynchronization treatments. The experimental design resulted in a $3 \times 2$ factorial arrangement of 6 treatments with the following number of cows used for statistical analyses: CONRCON ( $=224)$; CON-RCIDR ( $=114)$; CED-RCON $(\mathrm{n}=205)$; CED-RCIDR ( $\mathrm{n}=116)$; CTAI-RCON ( $\mathrm{n}=$ 174); and CTAI-RCIDR ( $\mathrm{n}=144)$.

\section{BCS and Milk Yield}

Cows were scored for body condition ( $1=$ emaciated, 5 = obese) on study d 3,35 , and 62 as described by Ferguson et al. (1994). For the purpose of analyzing the effects of BCS on the incidence of anestrous cows, estrus-detection rate, pregnancy rate, and pregnancy loss, cows were classified according to BCS on study d 3,35 , and 62 as thin if the BCS was $\leq 2.75$, or moderate if the BCS was $>2.75$. In addition, cows were classified according to a change in BCS from study d 3 to 62 . Yield of $3.5 \% \mathrm{FCM}$ was recorded monthly for individual cows during the first $3 \mathrm{mo}$ in lactation to determine the effect of milk yield on cyclicity, estrus-detection rate, pregnancy rate, and pregnancy loss.

\section{Blood Samples, Progesterone ELISA, and Characterization of Anestrous Cows}

Blood ( $7 \mathrm{~mL}$ ) was sampled from the median coccygeal vein or artery using evacuated tubes (Becton Dickinson, Franklin Lakes, NJ) containing $\mathrm{K}_{2}$ EDTA on study d 35,49 , and 62 , which corresponded to the injections of $\mathrm{PGF}_{2 \alpha}$ during presynchronization (d 35 and 49) and initiation of the Ovsynch protocol (d 62). On study d 49 , blood samples from cows in the CED and CTAI treatments were collected $30 \mathrm{~min}$ after removal of the CIDR insert to avoid a confounding effect of exogenous progesterone on concentrations in plasma of anestrous cows (Cerri et al., 2005b). Samples were immediately placed in ice and transported to the laboratory within $5 \mathrm{~h}$ of collection. Blood tubes were centrifuged at 2,000 $\times g$ for $15 \mathrm{~min}$ for plasma separation. Plasma samples were frozen at $-25^{\circ} \mathrm{C}$ and later analyzed for progesterone using a previously validated ELISA (Cerri et al., 2004). The intraassay coefficient of variation (CV) was determined for each 96 -well plate, and a plasma sample containing $2.5 \mathrm{ng} / \mathrm{mL}$ was used in each plate to estimate the interassay CV. Sensitivity of the assay was 0.05 $\mathrm{ng} / \mathrm{mL}$, and the intra- and interassay $\mathrm{CV}$ were 5.7 and $8.1 \%$, respectively.

Cows having concentrations of progesterone $<1.0 \mathrm{ng} /$ $\mathrm{mL}$ in both of the first 2 blood samples were classified as anestrous, and cows with concentrations of progesterone $\geq 1 \mathrm{ng} / \mathrm{mL}$ in at least 1 of the first 2 samples were classified as cyclic. Anestrous cows having progesterone concentrations of $\geq 1.0 \mathrm{ng} / \mathrm{mL}$ on study d 62 were classified as having resumed postpartum cyclicity.

\section{Ovarian Ultrasonography and Ovulatory Responses}

Four hundred and sixty cows enrolled in the Ovsynch protocol for first AI had their ovaries examined by ultrasonography (5.0 MHz transrectal linear probe, Sonovet 2000; Alliance Medical, Bedford Hills, NY) at the first injection of GnRH of the Ovsynch protocol (d 62). In addition to the 460 cows, another 135 cows (total of 595) enrolled in the Ovsynch protocol had their ovaries examined by ultrasonography at the time of $\mathrm{PGF}_{2 \alpha}$ injection of the protocol (d 69). Maps of the ovaries were drawn and the size and location of the CL and 2 largest follicles were recorded. Cows were classified as ovulating to the first injection of GnRH of the Ovsynch protocol when the presence of a new CL was detected by ultrasonography on study d 69 .

\section{Detection of Estrus and Al}

Cows were observed daily, in the morning, for estrus based on removal of tail paint (All-Weather Paintstick; LA-CO Industries, Chicago, IL). Only cows from the $\mathrm{CON}$ and CED treatments received first $\mathrm{AI}$ on detection of estrus after study d 49. After first AI, all cows observed in estrus were reinseminated independently of the presynchronization or resynchronization treatments. One technician inseminated cows for $6 \mathrm{~d} / \mathrm{wk}$, which coincided with the majority of AI, but a relief technician inseminated cows for $1 \mathrm{~d} / \mathrm{wk}$. 


\section{Pregnancy Diagnosis and Calculation of Reproductive Outcomes}

Pregnancy was diagnosed at $31 \pm 3 \mathrm{~d}$ after first AI by ultrasonographic examination of the uterus and its contents, and was characterized by visualization of an embryo. Cows diagnosed as pregnant by ultrasonography were reexamined by palpation per rectum of the uterine contents at $60 \pm 3 \mathrm{~d}$ after AI. After the second postpartum AI, pregnancy was diagnosed by palpation per rectum of the uterine contents at $42 \pm 3 \mathrm{~d}$ after AI. At pregnancy diagnosis on d 31 after the first AI, nonpregnant cows that had not been reinseminated were enrolled in the Ovsynch protocol.

Pregnancy rate was calculated as the number of cows diagnosed as pregnant at different time points after the end of the voluntary waiting period divided by the number of cows enrolled in each of the treatments. According to the study design, $100 \%$ of the cows enrolled in this study received the first AI by study d 72. Therefore, the pregnancy rate after first $\mathrm{AI}$ is the number of cows that had become pregnant between the end of the voluntary waiting period and study d 72 , unless otherwise stated. For cows enrolled in the CON and CED treatments, additional pregnancy rates were calculated between study d 49 and 62 , because these cows were allowed to receive AI on detection of estrus. The pregnancy rate after the second postpartum AI was calculated as the number of cows that became pregnant after second AI divided by the number of cows that were not pregnant after first AI. Pregnancy loss was calculated as the number of cows that lost pregnancy from 31 to $60 \mathrm{~d}$ of gestation divided by the number of pregnant cows on d 31 after first AI.

\section{Study Design and Statistical Analyses}

The experimental design was a completely randomized block design. Cows were blocked by parity, BCS on study d 3 , and previous lactation milk yield (multiparous cows), and within each block were randomly assigned to 1 of 3 presynchronization protocols. After first AI, cows were blocked by presynchronization treatment and randomly assigned to 1 of 2 resynchronization protocols.

The number of experimental units initially planned per treatment (350 cows/treatment) was expected to provide enough replicates to detect statistical significance with a $6 \%$ unit difference in pregnancy rate between treatments, when pregnancy rate after first AI ranged from 30 to $40 \%(\alpha=0.05 ; \beta=0.20)$. Furthermore, the number of experimental units was expected to provide enough pregnant cows at $31 \mathrm{~d}$ after first $\mathrm{AI}$ to detect statistical significance with an $8 \%$ unit difference in pregnancy loss between treatments, when pregnancy loss between 31 and $60 \mathrm{~d}$ after $\mathrm{AI}$ ranged from 10 to $22 \%(\alpha=0.10 ; \beta=0.20)$.

Binomially distributed data, such as the induction of cyclicity, estrus-detection rate, pregnancy rate, pregnancy loss, and reinsemination rate, were analyzed by logistic regression using the LOGISTIC procedure of SAS (SAS Institute, 2001). All models included the presynchronization treatment (CON, CED, and CTAI), resynchronization treatment (RCON and RCIDR), interaction between presynchronization and resynchronization treatments, parity (primiparous and multiparous), cyclic status on study d 49 (anestrous and cyclic), and interactions between treatments and the respective explanatory variables. Other covariates such as BCS on study d 3, 35, and 62, BCS changes from study d 3 to 35 and from study d 3 to 62 , and milk yield during the first 3 mo of lactation were included in the model only when univariate analyses demonstrated a level of significance of $\leq 0.20$. Milk yield and BCS were analyzed as continuous and categorical variables with no difference in the results of statistical models. The final logistic regression model removed variables by a backward elimination based on the Wald statistics criterion when $P>0.20$. For comparison of pregnancy rates of cows in CON and CED inseminated on detection of estrus during the $13 \mathrm{~d}$ after presynchronization with $\mathrm{PGF}_{2 \alpha}$ with those of cows inseminated following the TAI (CTAI), data from 620 cows $(\mathrm{CON}=144 ; \mathrm{CED}=158$; CTAI $=$ 318) were analyzed using the same statistical model for pregnancy rates as described previously.

The interval between the end of the voluntary waiting period and first AI was analyzed by ANOVA using the GLM procedure of SAS (SAS Institute, 2001), and the model included presynchronization treatment, parity, cyclicity status on study d 49, BCS on study d 3, 35, and 62 , BCS changes from study d 3 to 35 and 3 to 62 , milk yield, and interactions. The interval between the end of the voluntary waiting period and first AI for cows enrolled in the CON and CED treatments was analyzed by survival analysis using the product limit method of the Kaplan-Meier model by the LIFETEST procedure of SAS (SAS Institute, 2001) to assess the effect of the presynchronization protocol on days after the end of the voluntary waiting period when cows were inseminated.

The interval between first and second postpartum AI was analyzed by ANOVA using the GLM procedure of SAS (SAS Institute, 2001), and the model in-cluded presynchronization treatment, resynchronization treatment, interaction between presynchronization and resynchronization treatments, parity, cyclicity status on study d 49, BCS on study d 35 and 62 , BCS change from study d 3 to 62 , and reinsemination method (detected in estrus vs. TAI). 
Table 1. Factors affecting cyclic status on study d 49 in lactating dairy cows

\begin{tabular}{|c|c|c|c|c|}
\hline Item & Cyclic, ${ }^{1} \%$ (no./no.) & $\mathrm{AOR}^{2}$ & $95 \% \mathrm{CI}^{3}$ & $P$ \\
\hline Parity & & & & 0.001 \\
\hline Multiparous & $68.5(397 / 580)$ & 1 & Referent & \\
\hline Primiparous & $45.9(178 / 388)$ & 0.33 & 0.25 to 0.44 & \\
\hline \multicolumn{5}{|l|}{$\mathrm{BCS}$} \\
\hline \multicolumn{4}{|l|}{ Study d 3} & 0.002 \\
\hline$>2.75$ & $60.4(541 / 896)$ & 1 & Referent & \\
\hline$\leq 2.75$ & $47.2(34 / 72)$ & 0.45 & 0.27 to 0.75 & \\
\hline \multicolumn{4}{|l|}{ Study d 35} & 0.09 \\
\hline$>2.75$ & $66.3(226 / 341)$ & 1 & Referent & \\
\hline$\leq 2.75$ & $55.7(349 / 627)$ & 0.75 & 0.53 to 1.05 & \\
\hline \multicolumn{4}{|l|}{ Study d 62} & 0.02 \\
\hline$>2.75$ & $66.5(254 / 382)$ & 1 & Referent & \\
\hline$\leq 2.75$ & $54.8(321 / 586)$ & 0.68 & 0.50 to 0.93 & \\
\hline \multicolumn{5}{|l|}{ Units of BCS loss } \\
\hline \multicolumn{4}{|l|}{ Study d 3 to 35} & 0.20 \\
\hline$<1.0$ & $60.5(506 / 836)$ & 1 & Referent & \\
\hline$\geq 1.0$ & $52.3(69 / 132)$ & 0.77 & 0.52 to 1.15 & \\
\hline \multicolumn{4}{|l|}{ Study d 3 to 62} & 0.61 \\
\hline$<1.0$ & $60.8(498 / 819)$ & 1 & Referent & \\
\hline$\leq 1.0$ & $51.7(77 / 149)$ & 0.89 & 0.57 to 1.39 & \\
\hline \multicolumn{4}{|l|}{ Milk yield ${ }^{4}$} & 0.61 \\
\hline Quartile 1 & $57.4(140 / 244)$ & 0.97 & 0.66 to 1.43 & \\
\hline Quartile 2 & $61.0(147 / 241)$ & 1.12 & 0.76 to 1.64 & \\
\hline Quartile 3 & $62.3(152 / 244)$ & 1.23 & 0.84 to 1.80 & \\
\hline Quartile 4 & $56.9(136 / 239)$ & 1 & Referent & \\
\hline
\end{tabular}

\footnotetext{
${ }^{1}$ Cows were classified as cyclic when the plasma progesterone concentration was $\geq 1 \mathrm{ng} / \mathrm{mL}$ on at least 1 of 2 sampling days (study d 35 and 49 ).

${ }^{2} \mathrm{AOR}=$ adjusted odds ratio.

${ }^{3} 95 \%$ CI $=95 \%$ confidence interval.

${ }^{4}$ Milk yield during the first 3 mo of lactation. Yields of milk ( \pm SD) for each quartile are as follows: quartile $1=34.2 \pm 6.2 \mathrm{~kg} / \mathrm{d} ;$ quartile $2=41.3 \pm 6.0 \mathrm{~kg} / \mathrm{d}$; quartile $3=45.6 \pm 7.0 ;$ quartile $4=51.3 \pm 8.8 \mathrm{~kg} / \mathrm{d}$.
}

\section{RESULTS}

\section{Milk Production and BCS}

Average BCS did not differ $(P=0.66)$ among treatments and averaged 3.0 for the first $62 \mathrm{~d}$ postpartum. Primiparous cows experienced greater BCS loss $(P<$ 0.001 ) from study d 3 to 35 (primiparous $=-0.59 \pm 0.02$ vs. multiparous $=-0.51 \pm 0.01$ ) and from study $\mathrm{d} 3$ to 62 (primiparous $=-0.57 \pm 0.02$ vs. multiparous $=-0.45$ \pm 0.02 ). Average milk yield during the first $3 \mathrm{mo}$ of lactation was similar $(P=0.74)$ for all treatments and averaged $35.2 \pm 0.2 \mathrm{~kg} / \mathrm{d}$ for primiparous cows and 48.1 $\pm 0.1 \mathrm{~kg} / \mathrm{d}$ for multiparous cows.

\section{Cyclicity Status on Study d 49 and Response to Presynchronization Treatments}

The proportion of cows classified as anestrous on study d 49 was similar $(P=0.47)$ among presynchronization treatments $(\mathrm{CON}=42.9 \%, \mathrm{CED}=40.6 \%, \mathrm{CTAI}=$ $38.1 \%)$. Cyclicity on study d 49 was affected by parity in that fewer $(P<0.01)$ primiparous than multiparous cows were cyclic (Table 1). Low BCS on study d 3 and 62 reduced $(P<0.02)$, and low BCS on study d 35 tended $(P=0.09)$ to reduce the proportion of cyclic cows on study d 49. However, changes in BCS from study d 3 to 35 or $\mathrm{d} 3$ to 62 , and milk yield during the first $3 \mathrm{mo}$ of lactation did not affect $(P>0.15)$ cyclic status on study d 49.

A greater $(P=0.007)$ proportion of anestrous cows from the CED and CTAI initiated cyclicity by study d 62 (Figure 2). Resumption of cyclicity by study d 62 for cows classified as anestrous on study d 49 was affected $(P<0.01)$ by parity (primiparous $=35.9 \%$ vs. multiparous $=45.9 \%)$, BCS on study d 62 (thin $=34.5 \%$ vs. moderate $=53.1 \%$ ), and BCS change from study $\mathrm{d} 3$ to 62 . Anestrous cows on $d 49$ that lost $\geq 1.0$ unit of BCS were less likely $(P=0.03)$ to be cyclic on study d 62 than anestrous cows that experienced a BCS loss of $<1.0$ (29.2 vs. $43.1 \%$ ). However, no interactions were detected between methods of presynchronization and other explanatory variables on the resumption of cyclicity in anestrous cows.

\section{Ovulation to First GnRH and Presence of CL at the Time of $P F_{2 \alpha}$ Injections of the Ovsynch Protocol}

The results of ovulation to the first GnRH injection of the Ovsynch protocol and the presence of $\mathrm{CL}$ at $\mathrm{PGF}_{2 \alpha}$ 


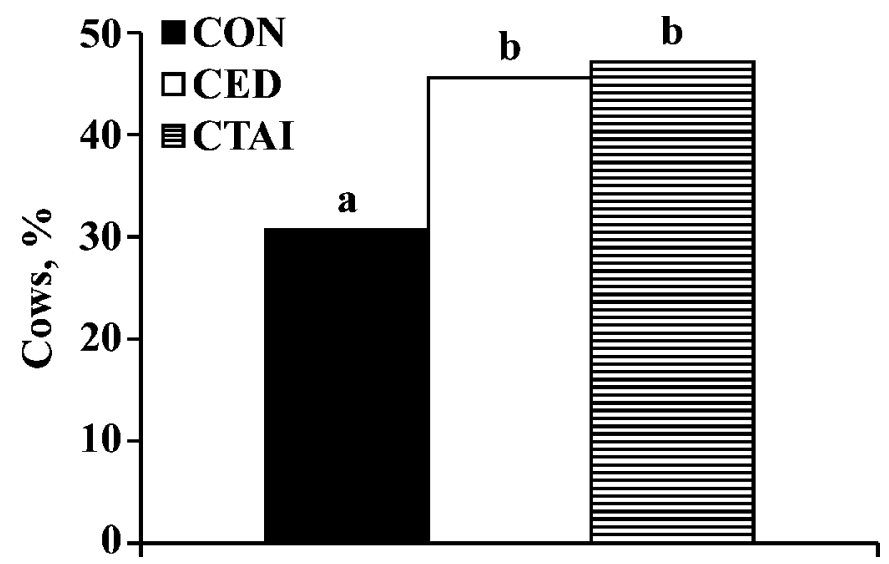

Figure 2. Effect of presynchronization protocol on the proportion of anestrous cows on study d 49 that resumed cyclicity by study d 62. All cows received 1 injection of $\mathrm{PGF}_{2 \alpha}$ on study d 35 and 49 , and study d 49 was set as the end of the voluntary waiting period for all treatments. $\mathrm{CON}=\mathrm{AI}$ on detection of estrus from study d 49 to 62 ; CED = controlled internal drug releasing (CIDR) insert from study d 42 to 49 and $\mathrm{AI}$ on detection of estrus from study d 49 to 62 ; CTAI = same as CED, but all cows received timed AI (TAI) on study d 72 after completion of the Ovsynch protocol. Cows in the CON and CED treatments not inseminated by study d 62 were enrolled in the Ovsynch protocol. ${ }^{\mathrm{a}, \mathrm{b}}$ Columns having different superscript letters differ $(P=0.007)$.

considered only cows that were enrolled in the TAI, because the CON and CED cows detected in estrus during presynchronization were not eligible for TAI. Ovulation to the first GnRH injection of the Ovsynch protocol tended $(P=0.06)$ to be affected by the method of presynchronization (Table 2). A greater $(P=0.03)$ proportion of CON cows ovulated to the first GnRH injection of the Ovsynch protocol than the proportion of CED cows. However, ovulation to the first GnRH of the Ovsynch program was not different between CTAI and the other presynchronization treatments. The proportion of cows presenting a $\mathrm{CL}$ at the time of $\mathrm{PGF}_{2 \alpha}$ injection of the Ovsynch protocol was affected $(P<$ 0.001 ) by the presynchronization protocol, and it was greatest for CTAI.

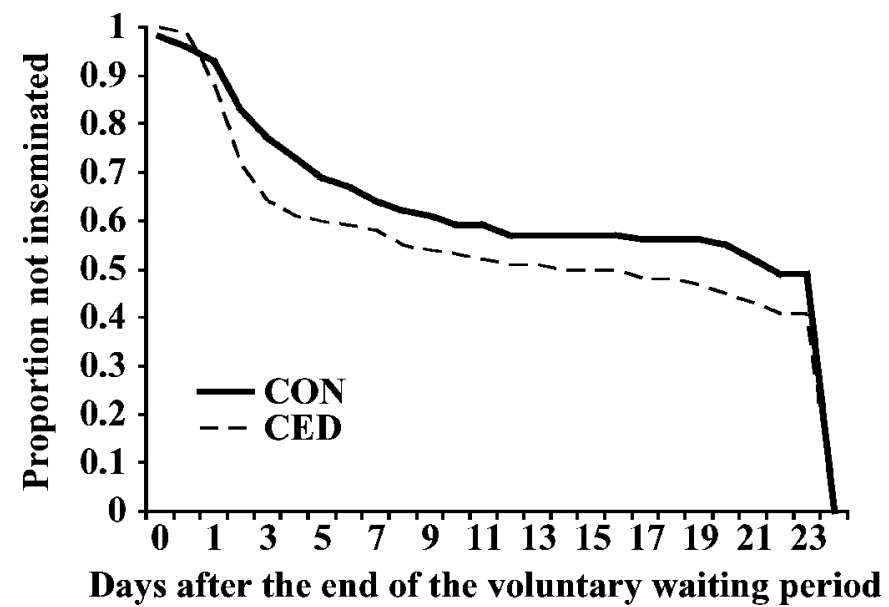

Figure 3. Survival curves for the interval between the end of the voluntary waiting period and first $\mathrm{AI}$ for cows in the CON $\left(\mathrm{PGF}_{2 \alpha}\right.$ on study d 35 and 49) and CED [PGF ${ }_{2 \alpha}$ on study d 35 and 49 and CIDR (controlled internal drug releasing) insert between study d 42 and 49] treatments $(P=0.003)$. Interval between the end of the voluntary waiting period and first AI were (mean \pm SEM): $\mathrm{CON}=$ $15.2 \pm 0.49$ and $\mathrm{CED}=13.6 \pm 0.52 \mathrm{~d}$. Median value for the interval between the end of the voluntary waiting period and the first AI were: $\mathrm{CON}=23$ and $\mathrm{CED}=17 \mathrm{~d}$.

\section{Reproductive Performance After First Al}

The interval between the end of the voluntary waiting period and first AI was affected $(P<0.001)$ by presynchronization treatment, and CTAI cows had the longest interval $(\mathrm{CON}=15.8 \pm 0.63, \mathrm{CED}=14.0 \pm 0.65, \mathrm{CTAI}=$ $23.8 \pm 0.53 \mathrm{~d}$ ) because of the study design. In addition, CED cows were inseminated at a faster rate $(P=0.003)$ than CON cows after the end of the voluntary waiting period (Figure 3). A tendency $(P=0.08)$ was observed for increased detection of estrus between 49 and 62 DIM for CED compared with CON cows ( 49.2 vs. $42.6 \%$, respectively), because the inclusion of a CIDR insert during presynchronization altered the pattern of detected estrus (Figure 4). The conception rate of CON and CED cows inseminated on detection of estrus be-

Table 2. Effect of presynchronization treatment on ovulation to the first GnRH injection and presence of a corpus luteum (CL) at the time of $\mathrm{PGF}_{2 \alpha}$ injection of the Ovsynch protocol

\begin{tabular}{|c|c|c|c|}
\hline \multirow[b]{2}{*}{ Effect } & \multicolumn{3}{|c|}{ Presynchronization $^{1}$} \\
\hline & $\mathrm{CON}$ & CED & CTAI \\
\hline Ovulation to GnRH, \% (no./no.) & $72.3^{\mathrm{a}}(94 / 130)$ & $57.9^{\mathrm{b}}(70 / 121)$ & $64.1^{\mathrm{ab}}(134 / 209)$ \\
\hline $\mathrm{CL}$ at $\mathrm{PGF}_{2 \alpha}, \%$ (no./no.) & $83.5^{\mathrm{b}}(142 / 170)$ & $75.4^{\mathrm{c}}(104 / 138)$ & $88.9^{\mathrm{a}}(255 / 287)$ \\
\hline \multicolumn{4}{|c|}{${ }^{\mathrm{a}-\mathrm{c}}$ Means having different superscript letters within a row differ $(P<0.05)$. } \\
\hline \multicolumn{4}{|c|}{$\begin{array}{l}{ }^{1} \text { All cows received } 1 \text { injection of } \mathrm{PGF}_{2 \alpha} \text { on study d } 35 \text { and } 49 \text {, and study d } 49 \text { was set as the end of the } \\
\text { voluntary waiting period for all treatments. CON = AI on detection of estrus from study d } 49 \text { to } 62 \text {; CED = } \\
\text { controlled internal drug releasing (CIDR) insert from study d } 42 \text { to } 49 \text { and AI on detection of estrus from } \\
\text { study d } 49 \text { to } 62 \text {; CTAI = same as CED, but all cows received timed AI (TAI) on study d } 72 \text { after completion } \\
\text { of the Ovsynch protocol. Cows in the CON and CED treatments not inseminated by study d } 62 \text { were enrolled } \\
\text { in the Ovsynch protocol. }\end{array}$} \\
\hline
\end{tabular}




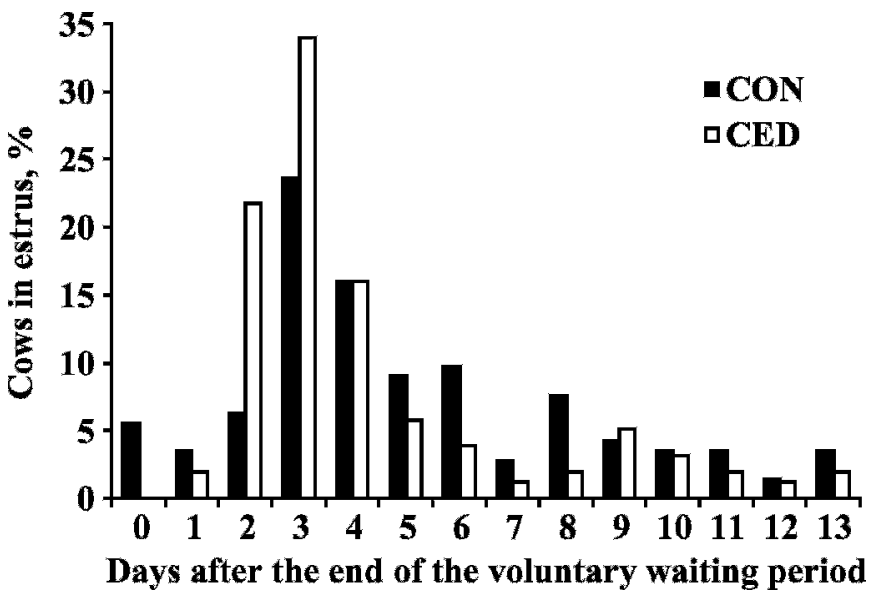

Figure 4. Distribution of estrus between the end of the voluntary waiting period (study d 49) and study d 62 for cows enrolled in the control (CON; $\mathrm{PGF}_{2 \alpha}$ on study d 35 and 49) and CED [controlled internal drug releasing (CIDR) estrus dectection; $\mathrm{PGF}_{2 \alpha}$ on study d 35 and 49 and CIDR insert between d 42 and 49] treatments.

tween study d 49 and 62 was not different at $31(\mathrm{CON}=$ 32.6 vs. $\mathrm{CED}=32.9 \% ; P=0.33)$ and $60 \mathrm{~d}(\mathrm{CON}=26.4$ vs. $\mathrm{CED}=27.2 \% ; P=0.95)$ after first AI. Because of the tendency for increased detection of estrus in CED compared with CON cows during this period, CED cows tended $(P=0.09)$ to have an increased pregnancy rate during the first $14 \mathrm{~d}$ after the end of the voluntary waiting period ( 16.2 vs. $13.9 \%$, respectively).

An interaction $(P=0.05)$ between presynchronization and resynchronization was observed for pregnancy rate on d 31 after AI, such that RCIDR cows had a greater pregnancy rate when presynchronized as CED and CTAI, but not as CON (Table 3). However, the resynchronization protocol reduced $(P=0.03)$ pregnancy loss from 31 to $60 \mathrm{~d}$ of gestation regardless of the presyn-

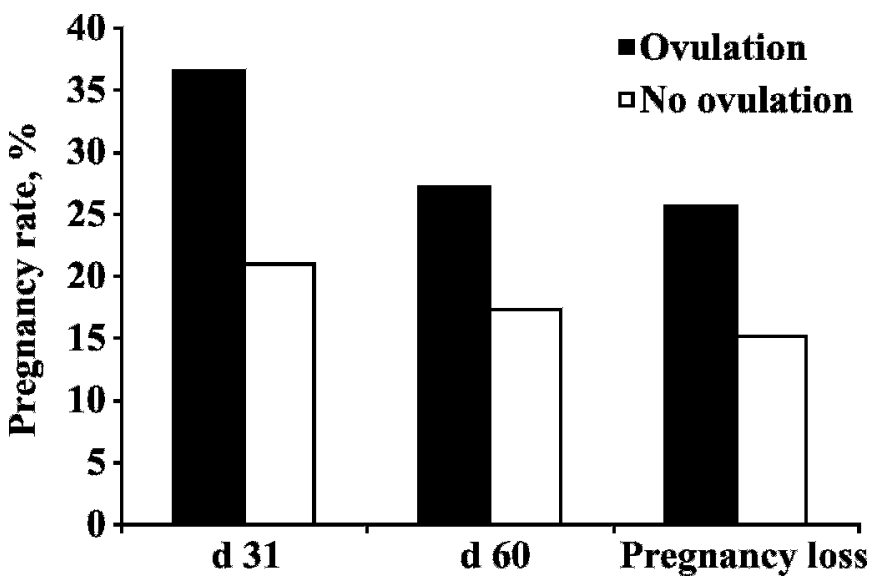

Figure 5. Effect of ovulation to the first $\mathrm{GnRH}$ injection of the Ovsynch protocol on pregnancy rates at $\mathrm{d} 31(P<0.001)$ and $60(P$ $<0.005)$ after AI and pregnancy loss $(P=0.10)$ between 31 and 60 $\mathrm{d}$ of gestation.

chronization protocol, which resulted in a greater $(P<$ 0.01) pregnancy rate on d 60 after first AI (Table 3 ).

Among cows in the CON and CED treatments, the pregnancy rate at $31 \mathrm{~d}$ after $\mathrm{AI}$ did not differ $(P=$ $0.66)$ when cows were inseminated either after detected estrus $(31.7 \%)$ or on TAI (30.4\%). For cows inseminated following TAI, ovulation to the first $\mathrm{GnRH}$ injection of the Ovsynch protocol increased $(P<0.01)$ the pregnancy rates on $\mathrm{d} 31$ and 60 after AI, although these cows tended $(P=0.10)$ to experience more pregnancy loss (Figure 5). Similarly, the presence of CL at the time of $\mathrm{PGF}_{2 \alpha}$ injection of the Ovsynch protocol increased $(P<$ 0.001 ) pregnancy rates on $d 31$ and 60 after AI, with no effect on pregnancy loss (Figure 6). When we compared the pregnancy rates of cows in CON and CED inseminated on detection of estrus in the $13 \mathrm{~d}$ after the

Table 3. Effect of presynchronization ${ }^{1}$ and resynchronization ${ }^{2}$ treatments on reproductive responses of lactating dairy cows after first AI

\begin{tabular}{|c|c|c|c|c|c|c|c|c|c|}
\hline \multirow[b]{2}{*}{ Item } & \multicolumn{6}{|c|}{ Reproductive protocol } & & & \\
\hline & $\mathrm{RCON}$ & RCIDR & $\mathrm{RCON}$ & RCIDR & $\mathrm{RCON}$ & RCIDR & $\mathrm{P}$ & $\mathrm{R}$ & $\mathrm{P} \times \mathrm{R}$ \\
\hline & & & {$[\%(\mathrm{n}$} & $/$ no.)] & & - & & & \\
\hline Pregnancy rate, $d 31$ & $31.7(71 / 224)$ & $24.6(28 / 114)$ & $29.3(60 / 205)$ & $39.7(46 / 116)$ & $36.8(64 / 174)$ & $43.1(62 / 144)$ & 0.01 & 0.32 & 0.05 \\
\hline Pregnancy rate, d 60 & $24.7(55 / 223)$ & $22.8(26 / 114)$ & $22.0(45 / 205)$ & $31.3(36 / 115)$ & $26.4(46 / 174)$ & $36.8(53 / 144)$ & 0.28 & 0.01 & 0.25 \\
\hline Pregnancy loss, d 31 to 60 & $21.4(15 / 70)$ & $7.1(2 / 28)$ & $25.0(15 / 60)$ & $20.0(9 / 45)$ & $28.1(18 / 64)$ & $14.5(9 / 62)$ & 0.21 & 0.03 & 0.47 \\
\hline
\end{tabular}

\footnotetext{
${ }^{1}$ All cows received 1 injection of $\mathrm{PGF}_{2 \alpha}$ on study d 35 and 49 , and study d 49 was set as the end of the voluntary waiting period for all treatments. $\mathrm{CON}=\mathrm{AI}$ on detection of estrus from study d 49 to 62; CED = controlled internal drug releasing (CIDR) insert from study d 42 to 49 and $\mathrm{AI}$ on detection of estrus from study d 49 to 62 ; CTAI = same as CED, but all cows received timed AI (TAI) on study d 72 after completion of the Ovsynch protocol. Cows in the CON and CED treatments not inseminated by study d 62 were enrolled in the Ovsynch protocol.

${ }^{2}$ Resynchronization: $\mathrm{RCON}=$ no further treatment; RCIDR = cows received a CIDR insert from $14 \pm 1$ to $21 \pm 1 \mathrm{~d}$ after first AI.

${ }^{3} P=$ effect of presynchronization (CON vs. CED vs. CTAI); $\mathrm{R}=$ effect of resynchronization (RCON vs. RCIDR); $\mathrm{P} \times \mathrm{R}=$ interaction of $\mathrm{P}$ $\times \mathrm{R}$.
} 


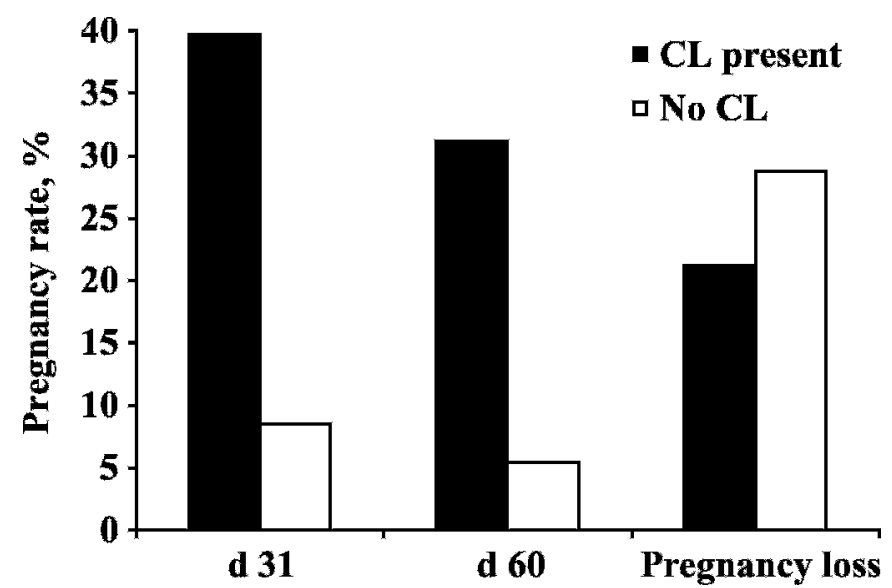

Figure 6. Effect of the presence of corpus luteum (CL) at the time of $\mathrm{PGF}_{2 \alpha}$ injection of the Ovsynch protocol on pregnancy rates on $\mathrm{d}$ $31(P<0.001)$ and $60(P<0.001)$ after AI and pregnancy loss $(P=$ 0.41 ) between $\mathrm{d} 31$ and 60 of gestation.

second $\mathrm{PGF}_{2 \alpha}$ of the presynchronization protocol with those of CTAI, there was a tendency $(P=0.09)$ for CTAI cows to have greater pregnancy rates $31 \mathrm{~d}$ after $\mathrm{AI}$ than the $\mathrm{CON}$ and $\mathrm{CED}$ cows $(\mathrm{CON}=32.6$ vs. $\mathrm{CED}=32.9$ vs. CTAI $=39.6 \%$ ); however, this tendency was not observed at $60 \mathrm{~d}(\mathrm{CON}=26.4$ vs. $\mathrm{CED}=27.2$ vs. $\mathrm{CTAI}=$ $31.1 \% ; P=0.50)$ after AI.

Cows classified as anestrous on study d 49 had a longer $(P<0.001)$ interval between the end of the voluntary waiting period and first AI compared with cyclic cows (Table 5). Furthermore, anestrous cows had smaller $(P<0.001)$ estrous detection from study d 49 to 62 than cyclic cows. Cows cycling by study d 49 had greater $(P<0.001)$ pregnancy rates than anestrous cows on $\mathrm{d} 31$ and 60 after AI, and these responses were observed regardless of presynchronization or resynchronization treatments. For CON and CED, cyclicity increased the detection of estrus and conception after the end of the voluntary waiting period, which resulted in an increased $(P<0.001)$ pregnancy rate in the first $14 \mathrm{~d}$ of AI. When pregnancy rates at 31 and $60 \mathrm{~d}$ after first AI were evaluated for cows according to the resumption of cyclicity after study d 49, those that remained anestrous had considerably smaller pregnancy rates than cows that were either cyclic or that had resumed cyclicity between study d 49 and 62 (Table 6).

\section{Reproductive Performance After Second AI}

The interval between first and second AI was not affected $(P=0.44)$ by the presynchronization protocol. Similarly, presynchronization did not influence the reinsemination of nonpregnant cows before a diagnosis of pregnancy (Table 4). However, the resynchronization protocol affected the pattern of return to estrus (Figure 7 ) and the interval between AI such that cows in the RCON treatment had shorter $(P=0.03)$ intervals than RCIDR cows ( $35.1 \pm 0.61$ vs. $36.7 \pm 0.68 \mathrm{~d}$, respectively). In spite of changes in the reinsemination interval, resynchronization did not influence $(P=0.18)$ the proportion of nonpregnant cows reinseminated before pregnancy diagnosis $(\mathrm{RCON}=59.4 \% \mathrm{vs} . \mathrm{RCIDR}=54.6 \%)$.

Presynchronization did not affect the pregnancy rate after second $\mathrm{AI}(\mathrm{CON}=25.4 \%, \mathrm{CED}=33.3 \%, \mathrm{CTAI}=$ 26.6\%; Table 4). Similarly, the pregnancy rate after second AI did not differ between resynchronization protocols for the different intervals after CIDR insert removal (Table 4).

Anestrous cows on study d 49 tended $(P=0.08)$ to have a longer interval between AI (Table 5). Similar to the first AI, anestrous cows also had a lower $(P=0.08)$ pregnancy rate than cyclic cows after the second postpartum AI.

Cows diagnosed as nonpregnant to the first $\mathrm{AI}$ and reinseminated at a fixed time after completion of the Ovsynch protocol had a greater $(P=0.02)$ pregnancy rate than cows reinseminated on detection of estrus (54/152, $35.5 \%$ vs. $125 / 480,26.0 \%$, respectively). No interactions were observed between the initial treatments (presynchronization and resynchronization) and method of second AI on the second insemination pregnancy rate.

\section{First and Second Service}

The proportion of cows pregnant after the first and second postpartum AI was not influenced by the presynchronization method, but more $(P=0.002)$ RCIDR than RCON cows were pregnant after 2 AI (Table 4). Similarly, a greater $(P=0.002)$ proportion of cyclic than anestrous cows became pregnant after the first 2 postpartum AI (Table 5).

\section{DISCUSSION}

The prevalence of anestrous cows after the end of the voluntary waiting period is an important factor affecting the reproductive efficiency of dairy herds (Rhodes et al., 2003; Santos et al., 2004b). In the present study, $40.6 \%$ of the cows were classified as anestrous at 49 DIM, which is greater than previously reported in some (Moreira et al., 2001; Cerri et al., 2004; Santos et al., 2004a), but not all, studies (El-Zarkouny et al., 2004). Cyclicity has been evaluated in the first 60 to 70 DIM (Cerri et al., 2004; El-Zarkouny et al., 2004; Galvão et al., 2004), whereas the current study evaluated cyclicity in the first 49 DIM. Delayed resumption of ovulation 
Table 4. Effect of presynchronization ${ }^{1}$ and resynchronization ${ }^{2}$ treatments on reproductive responses of lactating dairy cows after the second postpartum AI

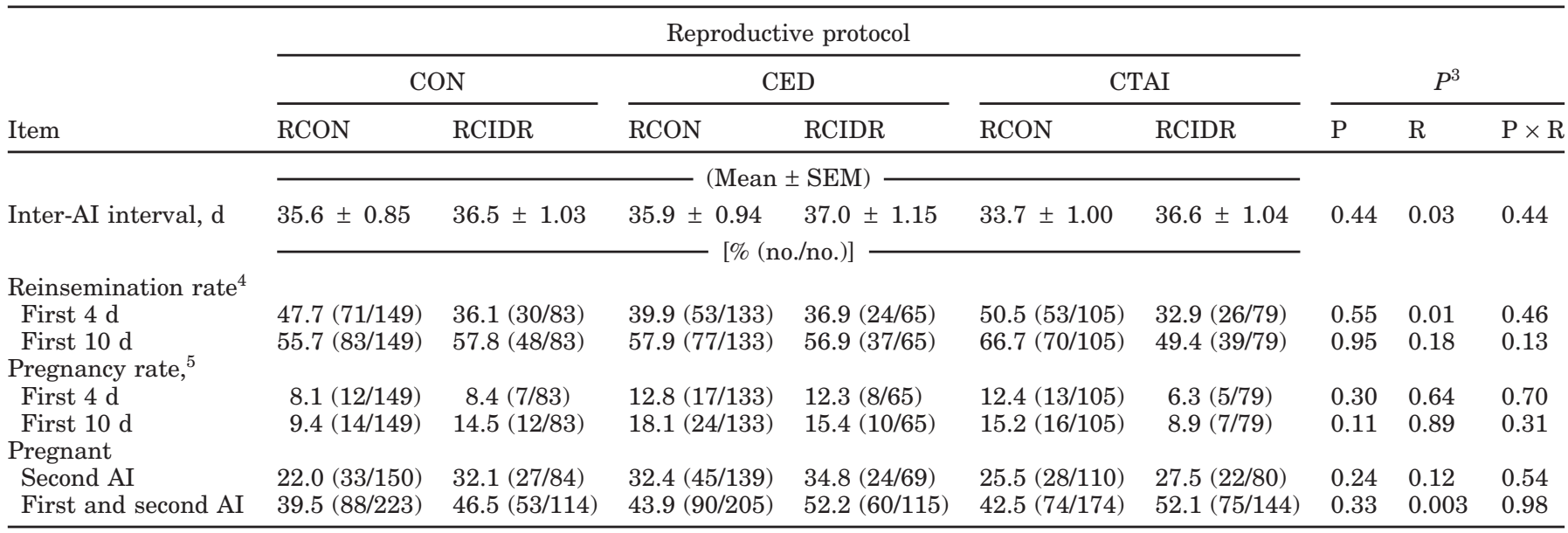

${ }^{1}$ All cows received 1 injection of $\mathrm{PGF}_{2 \alpha}$ on study d 35 and 49 , and study d 49 was set as the end of the voluntary waiting period for all treatments. $\mathrm{CON}=\mathrm{AI}$ on detection of estrus from study d 49 to 62 ; CED = controlled internal drug releasing (CIDR) insert from study d 42 to 49 and $\mathrm{AI}$ on detection of estrus from study d 49 to 62; CTAI = same as CED, but all cows received timed AI (TAI) on study d 72 after completion of the Ovsynch protocol. Cows in the CON and CED treatments not inseminated by study d 62 were enrolled in the Ovsynch protocol.

${ }^{2}$ Resynchronization: $\mathrm{RCON}=$ no further treatment; RCIDR = cows received CIDR insert from $14 \pm 1$ to $21 \pm 1 \mathrm{~d}$ after first AI.

${ }^{3} P=$ effect of presynchronization (CON vs. CED vs. CTAI); $\mathrm{R}=$ effect of resynchronization (RCON vs. RCIDR); $\mathrm{P} \times \mathrm{R}=$ interaction between $\mathrm{P}$ and $\mathrm{R}$.

${ }^{4}$ Proportion of cows reinseminated before pregnancy diagnosis, either until the first $4 \mathrm{~d}$ after CIDR insert removal (d $14 \pm 1$ to $25 \pm 1$ after first AI) or until the day of pregnancy diagnosis (d $14 \pm 1$ to $31 \pm 3$ after first AI).

${ }^{5}$ Pregnancy rate after second postpartum AI before pregnancy diagnosis, either until the first $4 \mathrm{~d}$ after removal of the CIDR insert ( $\mathrm{d} 14$ \pm 1 to $25 \pm 1$ after first AI) or until the day of pregnancy diagnosis (d $14 \pm 1$ to $31 \pm 3$ after first AI).

postpartum is related to the magnitude of negative energy balance and the timing of its nadir value, with the first ovulation typically occurring at approximately 10

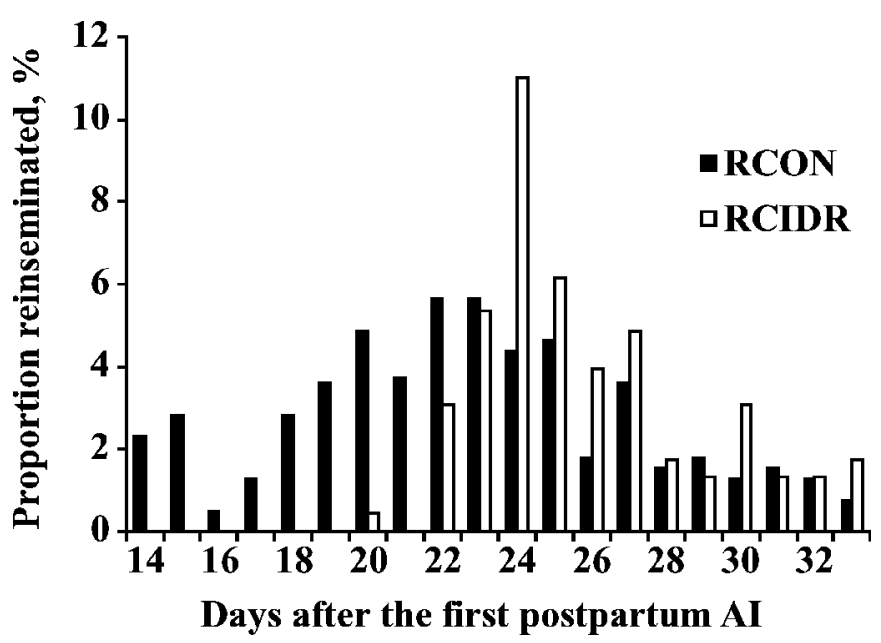

Figure 7. Effect of resynchronization protocol on pattern of return to estrus after first AI. Proportion of cows reinseminated between 14 and $25 \mathrm{~d}$ after first AI was greater $(P=0.01)$ for cows in the RCON [no controlled internal drug releasing (CIDR) insert] than in the RCIDR (CIDR insert from $14 \pm 1$ to $21 \pm 1 \mathrm{~d}$ after first AI) treatments $(\mathrm{RCON}=45.7$ vs. $\mathrm{RCIDR}=35.2 \%)$. $\mathrm{d}$ after the nadir of the negative energy balance postpartum (Beam and Butler, 1999).

Body condition reflects the amount of body reserves (mostly body fat; Ferguson et al., 1994), and changes in BCS after calving are used as an indicator of the energy status of dairy cows. In the present study, cows that presented BCS $\leq 2.75$ on study d 3,35 , and 62 were more likely to be classified as anestrous on study $d$ 49. Previous studies have demonstrated an increased proportion of anestrous cows as the BCS decreased at the time of initiation of the Ovsynch protocol (Moreira et al., 2001). Furthermore, when the BCS increased from 2.25 to 3.25 , a quadratic decrease in the incidence of anestrous cows was detected during the first $63 \mathrm{~d}$ postpartum (Santos et al., 2004a). Although Beam and Butler (1999) have demonstrated that cows experiencing more severe BCS loss after parturition have delayed resumption of ovulation, this was not observed in the present study.

Insertion of a CIDR insert for $7 \mathrm{~d}$, starting at approximately 42 DIM, increased induction of cyclicity by study d 62 in anestrous cows in the current study. Anestrous cows have continuous development of follicles to variable sizes, but ovulation does not occur, which is related either to follicles that do not secrete sufficient estradiol, to increased negative feedback of estradiol on $\mathrm{GnRH}$ 
Table 5. Effect of cyclic status on study d 49 on reproductive responses of lactating dairy cows after the first and second postpartum AI

\begin{tabular}{|c|c|c|c|}
\hline \multirow[b]{2}{*}{ Item } & \multicolumn{2}{|c|}{ Cyclic status $^{1}$} & \multirow[b]{2}{*}{$P$} \\
\hline & Anestrous & Cyclic & \\
\hline \multicolumn{4}{|l|}{ First AI } \\
\hline Interval to first $\mathrm{AI},{ }^{2} \mathrm{~d}( \pm \mathrm{SEM})$ & $19.4 \pm 0.48$ & $16.5 \pm 0.43$ & 0.001 \\
\hline Estrus-detection rate ${ }^{3} \%$ (no./no.) & $31.0(85 / 274)$ & $56.5(216 / 382)$ & 0.001 \\
\hline 14-d pregnancy rate, ${ }^{4} \%$ (no./no.) & $6.9(19 / 274)$ & $20.9(80 / 382)$ & 0.001 \\
\hline \multicolumn{4}{|l|}{ Pregnancy rate, \% (no./no.) } \\
\hline d 31 & $26.5(104 / 393)$ & $39.1(225 / 575)$ & 0.001 \\
\hline d 60 & $20.9(82 / 393)$ & $31.1(178 / 573)$ & 0.001 \\
\hline \multicolumn{4}{|l|}{ Pregnancy loss, \% (no./no.) } \\
\hline d 31 to 60 & $21.2(22 / 104)$ & $20.2(45 / 223)$ & 0.81 \\
\hline \multicolumn{4}{|l|}{ Second AI } \\
\hline Interval between $\mathrm{AI}{ }^{5} \mathrm{~d}( \pm \mathrm{SEM})$ & $36.6 \pm 0.65$ & $35.3 \pm 0.64$ & 0.08 \\
\hline Pregnancy rate, \% (no./no.) & $25.6(70 / 273)$ & $30.2(101 / 304)$ & 0.08 \\
\hline Pregnant after first and second AI, \% (no./no.) & $39.2(154 / 393)$ & $49.4(284 / 575)$ & 0.002 \\
\hline \multicolumn{4}{|c|}{$\begin{array}{l}{ }^{1} \text { Cows were classified as cyclic when the plasma progesterone concentration was } \geq 1 \mathrm{ng} / \mathrm{mL} \text { in at least } 1 \\
\text { of } 2 \text { sampling days (study d } 35 \text { and } 49 \text { ). }\end{array}$} \\
\hline \multicolumn{4}{|c|}{$\begin{array}{l}{ }^{2} \text { Interval between the end of the voluntary waiting period (study d } 49 \text { ) and the first AI for cows inseminated } \\
\text { on detection of estrus in presynchronization treatments control (CON) and controlled internal drug releasing } \\
\text { estrus detection (CED). }\end{array}$} \\
\hline \multirow{2}{*}{\multicolumn{4}{|c|}{$\begin{array}{l}{ }^{3} \text { Estrus-detection rate between study d } 49 \text { and } 62 \text { for cows enrolled in presynchronization treatments } \\
\text { CON and CED. }\end{array}$}} \\
\hline & & & \\
\hline \multicolumn{4}{|c|}{${ }^{4}$ Pregnancy rate for cows inseminated on detection of estrus between 49 and 62 DIM. } \\
\hline
\end{tabular}

or LH secretion, or simply to a lack of hypothalamic responsiveness to estradiol (Schillo, 1992). The mechanism of action of exogenous progesterone in reestablishing cyclicity is not completely elucidated, but progesterone is likely to reestablish the number of estrogen receptors in the medial basal hypothalamus, which reestablishes responsiveness to estradiol, resulting in a preovulatory LH surge (Gumen and Wiltbank, 2005). Furthermore, cows that received a CIDR insert initially presented lesser pulse frequency of LH (Nation et al., 2000), and this could lead to increased storage of $\mathrm{LH}$ in the pituitary gland (Johnson and Ulberg, 1967). After progesterone withdrawal, cows experience increased pulse frequency and mean concentrations of $\mathrm{LH}$, increased numbers of LH receptors in the granulosa and theca cells (Inskeep et al., 1988), increased estradiol production by the follicles, and an estradiol-stimulated LH surge and ovulation (Rhodes et al., 2003; Gumen and Wiltbank, 2005).

Because the progesterone from the CIDR insert increased induction of cyclicity in anestrous cows, use of the CIDR insert during the presynchronization treatment tended to increase the number of cows inseminated on detection of estrus before study d 62 , resulting in a shorter interval from the end of the voluntary waiting period to first AI in CED compared with CON cows. Previous studies have demonstrated that cyclic cows are more likely to be detected in estrous than anestrous cows (Cerri et al., 2004; Santos et al., 2004a), and use of exogenous progesterone results in induction of cyclicity

Table 6. Effect of cyclic status on study d 49 and 62 on reproductive responses of lactating dairy cows after the first AI

\begin{tabular}{|c|c|c|c|c|}
\hline \multirow[b]{2}{*}{ Reproductive response } & \multicolumn{3}{|c|}{ Resumption of postpartum cyclicity ${ }^{1}$} & \multirow[b]{2}{*}{$P$} \\
\hline & Cyclic d 49 & Cyclic d 62 & Anestrous d 62 & \\
\hline \multicolumn{5}{|c|}{ Pregnancy rate, \% (no./no.) } \\
\hline d 31 & $39.1(225 / 575)$ & $35.2(56 / 159)$ & $20.6(48 / 233)$ & 0.001 \\
\hline d 60 & $31.1(178 / 573)$ & $27.0(43 / 159)$ & $16.7(39 / 233)$ & 0.001 \\
\hline \multicolumn{5}{|c|}{ Pregnancy loss, \% (no./no.) } \\
\hline 31 to 60 & $20.2(45 / 223)$ & $23.2(13 / 56)$ & $18.8(9 / 48)$ & 0.71 \\
\hline
\end{tabular}

${ }^{1}$ For study d 49 , cows were classified as cyclic if the plasma progesterone concentration was $\geq 1 \mathrm{ng} / \mathrm{mL}$ on at least 1 of 2 sampling days (samples collected on study d 35 and 49), whereas for study d 62, anestrous cows on d 49 were considered to have resumed cyclicity if the plasma progesterone concentration was $\geq 1$ $\mathrm{ng} / \mathrm{mL}$ at study d 62 . 
and better synchronization of estrus in lactating dairy cows (Rhodes et al., 2003). Use of a CIDR insert during the presynchronization protocol also could have increased the estrus-detection rate by inhibiting the occurrence of estrus and ovulation in cows that had spontaneous luteolysis during treatment with the CIDR insert and by synchronizing their estrus and ovulation after removal of the CIDR insert (Chenault et al., 2003; El-Zarkouny and Stevenson, 2004). In fact, more than $55 \%$ of the cows observed in estrus from the CED treatment were detected within $4 \mathrm{~d}$ after removal of the CIDR insert, whereas only $46.3 \%$ of CON cows were observed in estrus during the same period.

For ovulatory responses, a subsample of cows not detected in estrus from the CON and CED treatments and a subsample of CTAI cows were evaluated. Cows in the CON treatment had a tendency for greater incidence of ovulation after the first $\mathrm{GnRH}$ of the Ovsynch protocol compared with CED cows. This could be explained by the different pattern of expressed estrus observed after the end of the voluntary waiting period between these treatments. Of the CED and CON cows subjected to TAI, $63.5 \%$ were cyclic on study d 62 , suggesting that they ovulated before enrollment in the Ovsynch, but were not detected in estrus. The majority of CED cows observed in estrus were inseminated within $4 \mathrm{~d}$ after the presynchronization. Therefore, it is reasonable to suggest that the majority of cyclic cows from the CED treatment enrolled in the Ovsynch protocol received the first injection of $\mathrm{GnRH}$ between $\mathrm{d} 9$ and 13 of the estrous cycle, whereas CON cows had a more disperse interval. Vasconcelos et al. (1999) and Cerri et al. (2005a) demonstrated that ovulatory response to the first GnRH of the Ovsynch protocol depends on the stage of the estrous cycle when the treatment is given. Because estrus was less tightly synchronized in the CON treatment, it is possible that a greater proportion of these cows enrolled in the Ovsynch protocol received the first $\mathrm{GnRH}$ injection when follicles were responsive to $\mathrm{LH}$ and capable of ovulating, likely before $\mathrm{d} 9$ of the estrous cycle. Nevertheless, it cannot be discounted that AI during the presynchronization might have altered ovulatory responses to $\mathrm{GnRH}$ because only a select portion of the CON and CED cows were evaluated.

The proportion of cows having a CL at the time of $\mathrm{PGF}_{2 \alpha}$ injection of the Ovsynch protocol was greater for cows in the CTAI treatment. Although the proportion of cows from the CON and CTAI treatments that responded to the first injection of GnRH did not differ, a greater proportion of CTAI cows enrolled in the Ovsynch protocol were classified as cyclic on study d 62, which could have led to an increased proportion of cows presenting a $\mathrm{CL}$ at the time of $\mathrm{PGF}_{2 \alpha}$. In fact, the cyclic status at $49 \mathrm{DIM}$ influenced $(P=0.02)$ the presence of CL and a greater proportion of cyclic (89.1\%) than anestrous (79.0\%) cows were observed with a CL at the $\mathrm{PGF}_{2 \alpha}$ injection of the Ovsynch protocol. The reduced proportion of cows in the CED treatment that had a CL at the time of $\mathrm{PGF}_{2 \alpha}$ is likely due to a reduced response to the first GnRH injection of the Ovsynch protocol.

Independent of the presynchronization treatment, cows enrolled in the Ovsynch protocol that responded to the first GnRH injection and those that had a CL at the time of $\mathrm{PGF}_{2 \alpha}$ injection had increased pregnancy rates at 31 and $60 \mathrm{~d}$ after AI. This is in accordance with previous studies demonstrating that the greatest pregnancy rate was achieved when cows ovulated to the first GnRH injection of the Ovsynch protocol (Vasconcelos et al., 1999), which is probably related to the recruitment of a new follicular wave resulting in the ovulation of a more fertile ovum at TAI. When the Ovsynch protocol was initiated on $\mathrm{d} 3$ of the estrous cycle, ovulatory response to the first GnRH was poor, resulting in an extended period of dominance of the ovulatory follicles and compromised embryo quality compared with that of cows initiating the Ovsynch protocol on $d 6$ of the estrous cycle (Cerri et al., 2005a). Furthermore, cows that ovulated to the first $\mathrm{GnRH}$ of the Ovsynch protocol were more likely to have a CL at the time of $\mathrm{PGF}_{2 \alpha}$, which has been associated with a greater pregnancy rate (Moreira et al., 2001; Cerri et al., 2004; Galvão et al., 2004).

Reports of the effects of TAI on the fertility of dairy cows have been mixed, with some studies indicating a reduction in conception rates (Santos et al., 2004a; Tenhagen et al., 2004), but not others (Pursley et al., 1997; Cerri et al., 2004). In the current study, within the CON and CED cows, the pregnancy rate at $31 \mathrm{~d}$ after first AI did not differ between those inseminated after detected estrus following presynchronization and those subjected to the Ovsynch protocol. Similarly, when we compared the CON and CED cows inseminated at detected estrus with cows from CTAI, no differences were observed for pregnancy rates at 31 and $60 \mathrm{~d}$ after first AI. However, the conception rate after second postpartum AI was lower for cows inseminated on detection of spontaneous estrus (26\%) than for cows inseminated following the Ovsynch protocol (35.5\%). The lower conception rate after second postpartum AI in cows inseminated after detected estrus may result from poorer estrus-detection accuracy compared with that induced by 2 injections of $\mathrm{PGF}_{2 \alpha}$, as for first $\mathrm{AI}$ in the CON and CED cows. The proportion of dairy cows inseminated on detection of spontaneous estrus, but with concentrations of progesterone compatible with the luteal phase, was as high as 19\% (Sturman et al., 2000). 
These cows, which are erroneously detected in estrus, would have reduced conception rates.

The lack of differences in pregnancy rates at 31 and $60 \mathrm{~d}$ after AI between CON and CED indicates that use of the CIDR insert during presynchronization did not improve fertility. Reports on the benefits of incorporating a CIDR insert before AI on the pregnancy rates of dairy cows have been scarce. When the CIDR insert was incorporated during the TAI protocol, the benefits on fertility were observed in only 1 of 3 experiments, when cows were not presynchronized (El-Zarkouny et al., 2004; Galvão et al., 2004).

Resynchronization of lactating dairy cows with a CIDR insert from 14 to $21 \mathrm{~d}$ after AI altered the return to estrus in nonpregnant cows and reduced the reinsemination of nonpregnant cows until $4 \mathrm{~d}$ after the removal of the CIDR insert, but did not alter the proportion of cows reinseminated before pregnancy diagnosis. In a previous study, use of the CIDR insert in a similar manner resulted in increased reinsemination of nonpregnant cows (Chenault et al., 2003). The difference in findings between the current study and the study by Chenault et al. (2003) may be explained by the different periods observed for calculation of the reinsemination rate. Chenault et al. (2003) observed cows for estrus from 18 to $29 \mathrm{~d}$ after AI, whereas the present study evaluated reinsemination that occurred from the day of insertion of the CIDR insert to pregnancy diagnosis. When detection of estrus was evaluated from 14 to 21 $\mathrm{d}$ after AI, $42.6 \%$ of RCON cows observed in estrus before pregnancy diagnosis had already been reinseminated, whereas only $0.81 \%$ of the RCIDR cows were reinseminated during the same interval. Similar to our findings, El-Zarkouny and Stevenson (2004) also observed that use of a CIDR insert from 13 to $20 \mathrm{~d}$ after AI increased the synchrony of return to estrus, but failed to increase the reinsemination rate of nonpregnant cows during the $6 \mathrm{~d}$ after removal of the CIDR insert. Progesterone from the CIDR insert likely inhibited the occurrence of estrus even if spontaneous luteolysis occurred between 14 and $21 \mathrm{~d}$ after AI (El-Zarkouny and Stevenson, 2004). Nevertheless, changes in the pattern of return to estrus and condensing the expression of estrus during a shorter interval might prove beneficial in certain reproductive programs to allow producers to focus on detection of estrus of specific groups of cows over fewer days following removal of the insert.

Although RCIDR inhibited the return to estrus during treatment and did not improve the reinsemination of nonpregnant cows, an interaction was detected between the presynchronization and resynchronization treatments on the pregnancy rate at $31 \mathrm{~d}$ after first AI, in that resynchronization with the CIDR insert im- proved pregnancy rates of cows in the CED and CTAI groups. It is not clear why CON cows did not benefit from receiving a CIDR insert during the resynchronization protocol. Regardless of the presynchronization protocol, however, cows that received a CIDR insert from 14 to $21 \mathrm{~d}$ after first AI had reduced pregnancy losses, which improved pregnancy rates at $60 \mathrm{~d}$ after first AI. Similar improvements in embryonic survival were observed when the CIDR insert was inserted from 13 to $20 \mathrm{~d}$ after TAI (El-Zarkouny and Stevenson, 2004). It is possible that progesterone supplementation with the CIDR insert between 14 and $21 \mathrm{~d}$ after AI influenced embryonic development, but the results of this beneficial effect were not clearly seen by d 31 after AI. We did observe numerical differences $(4.1 \%$ units) in pregnancy at $\mathrm{d} 31$ after AI between RCON and RCIDR cows, but this was not sufficient to show a statistical effect. As gestation progresses, the proportion of cows that lose pregnancy increases. It is possible that with additional gestation time, cows in the RCIDR group were more capable of maintaining pregnancy, which eventually would result in statistical differences due to progesterone supplementation.

Some studies have evaluated the effect of supplemental progesterone from the CIDR insert on pregnancy. Treatment with a CIDR insert from 14 to $21 \mathrm{~d}$ after AI was associated with a reduced conception rate in response to the pretreatment AI (Chenault et al., 2003), and this effect was associated with an increased mucus score because of vaginal irritation. However, El-Zarkouny and Stevenson (2004) observed an improvement in embryo survival between 29 and $57 \mathrm{~d}$ of gestation when cows received a CIDR insert from d 13 to 20 after AI. In a meta-analysis, Mann and Lamming (1999) observed that supplemental progesterone significantly increased conception rates when administered before $d$ 6 after AI in lactating dairy cows. Similarly, treatment with a progesterone-releasing intravaginal device containing $1.55 \mathrm{~g}$ of progesterone after d 36 of gestation, for a period of $28 \mathrm{~d}$, increased fetal survival until d 90 of gestation in lactating dairy cows (Lopez-Gatius et al., 2004). Although the results of studies are conflicting, our results corroborate those of El-Zarkouny and Stevenson (2004) and Lopez-Gatius et al. (2004) and suggest that embryonic and fetal survival might be improved when lactating dairy cows receive progesterone from an intravaginal insert.

One of the factors that may increase the risk of pregnancy loss in lactating dairy cows is a reduction in circulating concentrations of progesterone. Recently, the mean increase in plasma concentration of progesterone in lactating dairy cows resulting from treatment with a CIDR insert was shown to be approximately 0.8 $\mathrm{ng} / \mathrm{mL}$ (Cerri et al., 2005b). Therefore, it is possible that 
increases in progesterone as small as $0.8 \mathrm{ng} / \mathrm{mL}$ might benefit pregnancy in lactating dairy cows, which are known to have low circulating progesterone (Wiltbank et al., 2006).

Anestrous cows had a marked reduction in reproductive performance and these effects were independent of treatment. Reduced detection of estrus and decreased pregnancy rates were observed in cows classified as anestrous compared with cyclic. Such effects in anestrous cows having delayed cyclicity, reduced detection of estrus (Cerri et al., 2004; Galvão et al., 2004; Santos et al., 2004a), and reduced pregnancy rates (Cerri et al., 2004; Galvão et al., 2004; Santos et al., 2004a) have been observed. When enrolled in a TAI program, anestrous cows do not benefit from presynchronization with $\mathrm{PGF}_{2 \alpha}$ (Moreira et al., 2001), which reduces the benefits of presynchronization on pregnancy (Moreira et al., 2001; Navanukraw et al., 2004). Anestrous cows also have reduced synchronized ovulation (Galvão et al., 2004), which compromises pregnancy likely by reducing fertilization or by influencing embryo quality when fertilization is delayed and oocyte quality is compromised. Furthermore, anestrous cows are more likely to experience short luteal cycles after first ovulation, which is linked to a decreased number of progesterone receptors and an increased number of oxytocin receptors in the endometrial cells resulting from inadequate exposure to progesterone, which might trigger premature release of $\mathrm{PGF}_{2 \alpha}$ and luteolysis (Zollers et al., 1993). All of these factors may play a role in reducing the reproductive performance of anestrous cows. Interestingly, cows initially classified as anestrous on study d 49 , but that resumed cyclicity by study $d 62$, had similar reproductive performance as those that were cyclic at $49 \mathrm{~d}$ postpartum. These results indicate that interventions to induce cyclicity before enrollment in a synchronization program improve the reproductive performance of dairy cows.

\section{CONCLUSIONS}

Use of CIDR inserts during presynchronization increased the proportion of anestrous cows that initiated cyclicity within $13 \mathrm{~d}$ after the end of the voluntary waiting period. Furthermore, presynchronization with a CIDR insert reduced the interval between the end of the voluntary waiting period and first AI, and tended to improve the estrus-detection rate. When the CIDR insert was used during presynchronization, however, a reduction in ovulation occurred after the first GnRH of the Ovsynch program, which suggests that the interval between presynchronization and initiation of the TAI program needs to be shortened to optimize ovulation after the GnRH and fertility. Cows that ovulated after the first GnRH of the Ovsynch protocol had greater pregnancy rates than those that did not ovulate. Although the CIDR insert used for resynchronization between 14 and $21 \mathrm{~d}$ after AI did not improve the reinsemination rates of nonpregnant cows, it increased the pregnancy rates on d 31 after first AI for cows that received a CIDR insert during presynchronization, and on $\mathrm{d} 60$ after first AI regardless of presynchronization because of reduced pregnancy losses between 31 and $60 \mathrm{~d}$ of gestation. The benefits of the CIDR insert during resynchronization on the pregnancy of dairy cows also were detected when both first and second AI were evaluated. Reproductive performance in dairy cows can be improved by incorporating a CIDR insert between 14 and $21 \mathrm{~d}$ after AI.

\section{ACKNOWLEDGMENTS}

This research was supported by grants from the National Association of Animal Breeders, Pfizer Animal Health, and the National Research Initiative Competitive Grant no. 2004-35203-14137 from the USDA Cooperative State Research, Education, and Extension Service to J. E. P. Santos. The authors thank Frank Hurtig of Merial for providing the Cystorelin and Frederico Moreira of Pfizer Animal Health for providing the Lutalyse Sterile Solution and Eazi Breed CIDR cattle inserts used in this study. Our gratitude also is extended to the owner and staff of the Rancho Teresita Dairy Farm.

\section{REFERENCES}

Beam, S. W., and W. R. Butler. 1999. Effects of energy balance on follicular development and first ovulation in postpartum dairy cows. J. Reprod. Fertil. Suppl. 54:411-424.

Cerri, R. L. A., H. M. Rutigliano, R. G. S. Bruno, R. C. Chebel, and J. E. P. Santos. 2005a. Effect of artificial insemination (AI) protocol on fertilization and embryo quality in high-producing dairy cows. J. Dairy Sci. 88(Suppl. 1):86. (Abstr.)

Cerri, R. L. A., H. M. Rutigliano, R. G. S. Bruno, and J. E. P. Santos. 2005b. Progesterone (P4) concentrations and ovarian response after insertion of a new or a $7 \mathrm{~d}$ used intravaginal P4 insert (IPI) in proestrus lactating cows. J. Dairy Sci. 88(Suppl. 1):37. (Abstr.)

Cerri, R. L., J. E. Santos, S. O. Juchem, K. N. Galvão, and R. C. Chebel. 2004. Timed artificial insemination with estradiol cypionate or insemination at estrus in high-producing dairy cows. J. Dairy Sci. 87:3704-3715.

Chenault, J. R., J. F. Boucher, K. J. Dame, J. A. Meyer, and S. L. Wood-Follis. 2003. Intravaginal progesterone insert to synchronize return to estrus of previously inseminated dairy cows. J. Dairy Sci. 86:2039-2049.

El-Zarkouny, S. Z., J. A. Cartmill, B. A. Hensley, and J. S. Stevenson. 2004. Pregnancy in dairy cows after synchronized ovulation regimens with or without presynchronization and progesterone. J. Dairy Sci. 87:1024-1037.

El-Zarkouny, S. Z., and J. S. Stevenson. 2004. Resynchronizing estrus with progesterone or progesterone plus estrogen in cows of unknown pregnancy status. J. Dairy Sci. 87:3306-3321.

Ferguson, J. O., D. T. Galligan, and N. Thomsen. 1994. Principal descriptors of body condition score in Holstein cows. J. Dairy Sci. 77:2695-2703. 
Galvão, K. N., J. E. P. Santos, S. O. Juchem, R. L. A. Cerri, A. C. Coscioni, and M. Villasenor. 2004. Effect of addition of a progesterone intravaginal insert to a timed insemination protocol using estradiol cypionate on ovulation rate, pregnancy rate, and late embryonic loss in lactating dairy cows. J. Anim. Sci. 82:35083517.

Gumen, A., and M. C. Wiltbank. 2005. Length of progesterone exposure needed to resolve large follicle anovular condition in dairy cows. Theriogenology 63:202-218.

Inskeep, E. K., T. D. Braden, P. E. Lewis, M. Garcia-Winder, and G. D. Niswender. 1988. Receptors for luteinizing hormone and follicle-stimulating hormone in largest follicles of postpartum beef cows. Biol. Reprod. 38:587-591.

Johnson, A. D., and L. C. Ulberg. 1967. Influence of exogenous progesterone on follicular cysts in dairy cattle. J. Dairy Sci. 50:758-761.

Lopez-Gatius, F., P. Santolaria, J. L. Yaniz, and R. H. Hunter. 2004. Progesterone supplementation during the early fetal period reduces pregnancy loss in high-yielding dairy cattle. Theriogenology 62:1529-1535.

Mann, G. E., and G. E. Lamming. 1999. The influence of progesterone during early pregnancy in cattle. Reprod. Domest. Anim. 34:269-274.

Moreira, F., C. Orlandi, C. A. Risco, R. Mattos, F. Lopes, and W. W. Thatcher. 2001. Effects of presynchronization and bovine somatotropin on pregnancy rates to a timed artificial insemination protocol in lactating dairy cows. J. Dairy Sci. 84:1646-1659.

Nation, D. P., C. R. Burke, G. Parton, R. Stevenson, and K. L. Macmillan. 2000. Hormonal and ovarian responses to a 5-day progesterone treatment in anoestrous dairy cows in the third week postpartum. Anim. Reprod. Sci. 63:13-25.

Navanukraw, C., D. A. Redmer, L. P. Reynolds, J. D. Kirsch, A. T. Grazul-Bilska, and P. M. Fricke. 2004. A modified presynchronization protocol improves fertility to timed artificial insemination in lactating dairy cows. J. Dairy Sci. 87:1551-1557.

NRC (National Research Council). 2001. Nutrient Requirements of Dairy Cattle. 7th ed. Natl. Acad. Press, Washington, DC.

Pursley, J. R., M. C. Wiltbank, J. S. Stevenson, J. S. Ottobre, H. A. Garverick, and L. L. Anderson. 1997. Pregnancy rates per artificial insemination for cows and heifers inseminated at a synchronized ovulation or synchronized estrus. J. Dairy Sci. 80:295-300.
Rhodes, F. M., S. McDougall, C. R. Burke, G. A. Verkerk, and K. L. Macmillan. 2003. Treatment of cows with an extended postpartum anestrous interval. J. Dairy Sci. 86:1876-1894.

Santos, J. E., S. O. Juchem, R. L. Cerri, K. N. Galvão, R. C. Chebel, W. W. Thatcher, C. S. Dei, and C. R. Bilby. 2004a. Effect of bST and reproductive management on reproductive performance of Holstein dairy cows. J. Dairy Sci. 87:868-881.

Santos, J. E., W. W. Thatcher, R. C. Chebel, R. L. Cerri, and K. N. Galvão. 2004b. The effect of embryonic death rates in cattle on the efficacy of estrus synchronization programs. Anim. Reprod. Sci. 82-83:513-535.

SAS Institute. 2001. SAS/STAT User's Guide, Release 8.2. SAS Inst. Inc., Cary, NC.

Schillo, K. K. 1992. Effects of dietary energy on control of luteinizing hormone secretion in cattle and sheep. J. Anim. Sci. 70:12711282 .

Stevenson, J. S., and A. P. Phatak. 2005. Inseminations at estrus induced by presynchronization before application of synchronized estrus and ovulation. J. Dairy Sci. 88:399-405.

Sturman, H., E. A. Oltenacu, and R. H. Foote. 2000. Importance of inseminating only cows in estrus. Theriogenology 53:1657-1667.

Tenhagen, B. A., M. Drillich, R. Surholt, and W. Heuwieser. 2004 Comparison of timed AI after synchronized ovulation to AI at estrus: Reproductive and economic considerations. J. Dairy Sci. 87:85-94.

Vasconcelos, J. L., R. W. Silcox, G. J. Rosa, J. R. Pursley, and M. C. Wiltbank. 1999. Synchronization rate, size of the ovulatory follicle, and pregnancy rate after synchronization of ovulation beginning on different days of the estrus cycle in lactating dairy cows. Theriogenology 52:1067-1078.

Wiltbank, M. C., H. Lopez, R. Sartori, S. Sangsritavong, and A. Gumen. 2006. Changes in reproductive physiology of lactating dairy cows due to elevated steroid metabolism. Theriogenology 65:17-29.

Zollers, W. G., Jr., H. A. Garverick, M. F. Smith, R. J. Moffatt, B. E. Salfen, and R. S. Youngquist. 1993. Concentrations of progesterone and oxytocin receptors in endometrium of postpartum cows expected to have a short or normal oestrus cycle. J. Reprod. Fertil. 97:329-337. 